\title{
Metallothioneins in the lung cancer
}

\author{
Bozena Werynska $^{1}$, Bartosz Pula ${ }^{2}$, Christopher Kobierzycki ${ }^{2,3}$, Piotr Dziegiel ${ }^{2,3}$, \\ Marzenna Podhorska-Okolow ${ }^{2}$
}

\author{
${ }^{1}$ Department of Pulmonology and Pulmonary Tumors, Wroclaw Medical University, Poland \\ ${ }^{2}$ Department of Histology and Embryology, Wroclaw Medical University, Poland \\ ${ }^{3}$ Department of Physiotherapy, Wroclaw University School of Physical Education, Poland
}

\begin{abstract}
Metallothioneins (MTs) are low weight proteins involved in several key cellular processes such as metal ions homeostasis, detoxification and scavenging of free radicals. Four groups of MTs are distinguished: MT-1, MT-2, MT-3 and MT-4. Regardless of the type, MTs are characterized by high content of cysteine, responsible for their biological properties such as binding of relevant zinc and copper ions, as well as toxic ions such as lead and cadmium. MTs were additionally shown to protect cells against oxidative stress damage and participate in differentiation, proliferation and/or apoptosis of normal and cancer cells. Many studies of different neoplasms showed association of elevated MTs levels with occurrence of chemo- and radiotherapy resistance and poor patients' outcome. In this review, we summarize and discuss the potential mechanism of action of metallotioneins in lung physiology and pathology. (Folia Histochemica et Cytobiologica 2015, Vol. 53, No. 1, 1-10)
\end{abstract}

Key words: metallothionein; lung cancer; non-small cell lung cancer; prognosis; proliferation

\begin{abstract}
Abbreviations: AC - adenocarcinoma, ARE - antioxidant response element, CCT-LC - chronic cadmium-treated lung cells, EMT - epithelial-to-mesenchymal transition, FGF - fibroblast growth factor, GIF — growth inhibitory factor, GRE - glucocorticoid response element, HIF-1 $\alpha$ - hypoxia-inducible factor- $1 \alpha, \mathrm{HO}-1$ - heme oxygenase- 1 , iNOS — inducible nitric oxide synthase, LCC — large-cell carcinoma, LPS - lipopolysaccharide, MRE - metal response element, MT - metallothionein, MTF-1 - metal regulatory transcription factor, NSCLC - non-small cell lung cancer, OVA - ovalbumin, SCC — squamous cell carcinoma, SCLC - small cell lung cancer, $\mathrm{SOD}$ - superoxide dismutase, TGF $\beta$ transforming growth factor $\beta$, VEGF-A - vascular endothelial growth factor $\mathrm{A}$
\end{abstract}

Correspondence address: B. Werynska, M.D., Ph.D.

Department of Pulmonology and Pulmonary Tumors

Wroclaw Medical University

Grabiszynska St. 105, 53-439 Wroclaw

tel.: +487133495 59, fax: +48713349596

e-mail: bozenawerynska@wp.pl

\section{Introduction}

Lung cancer is reported to be one of the malignancies with the highest mortality both in Poland and worldwide [1,2]. The majority of the diagnosed lung malignancies $(84 \%)$ belong to the group of non-small cell lung cancers (NSCLC), and they are divided into three histological subtypes: squamous cell carcinoma (SCC), adenocarcinoma (AC) and large-cell carcinoma (LCC). Small cell lung cancers (SCLC) account for approximately $14 \%$ of the diagnosed cases [3]. Despite improvements in diagnostics and treatment, majority of the cases are diagnosed in advanced clinical stages with unfavorable disease course. It is estimated that only $16 \%$ of the patients survive longer than 5 years [1]. Taking into account high mortality and poor patients' outcome, studies on new prognostic and predictive markers of lung cancer are necessary.

Metallothioneins (MTs) are highly conserved low weight proteins $(6-7 \mathrm{kDa})$ localized in the cytoplasm and cell nucleus. They were initially isolated from equine renal cortex and subsequently tested in other species [4]. A single MT molecule comprises 61 to 68 amino acids, which form two main domains designated as $\alpha$ and $\beta[4,5]$. Studies on rodents enabled 
distinguishing four groups of metallothioneins: MT-1, MT-2, MT-3 and MT-4 [5, 6]. In humans, MTs are encoded by 17 genes, from which thirteen code for MT-1, two for MT-2 and one gene each codes for MT-3 and MT-4 [7-9]. Since now, ten genes were identified which encode functional MT proteins, MT-1A, MT-1B, MT-1E, MT-1F, MT-1G, MT-1H, MT-1X, MT-2A, MT-3, MT-4, and seven genes coding for non-functional isoforms: MT-1C, MT-1D, MT-1I, MT-1J, MT-1K, MT-1L and MT-2B [7, 10]. Recently, a gene called MT-like $5(M T L-5)$ and closely related in structure to other MTs was identified in mice testes. $M T L-5$ encodes protein tesmin, differentially regulating meiosis in male and female cells [11]. Regardless of the type, MTs are characterized by high content of cysteine (up to one third of all amino acids), which thiol groups are responsible for their biological properties such as binding of relevant zinc and copper ions, as well as toxic ions such as lead, cadmium and mercury. Due to their properties, MTs participate in zinc and copper ions homeostasis and are capable of detoxifying the organism of other toxic metals [6]. MTs were additionally shown to protect cells against oxidative stress damage and participate in cell proliferation and/or apoptosis [4]. Although MT isoforms possess similar structure, their biological role may vary depending on cell type. Since now MT-1 and MT-2 isoforms are the best characterized and are ubiquitously expressed in normal, as well as cancer cells $[4,12,13]$. MT-3, isolated first from human brains affected by Alzheimer disease, was initially regarded as specific for nervous system; however, later studies demonstrated its expression also in cancer cells [14-18]. The MT-4 is so far the least characterized member of the MTs family and its expression has been mainly observed within the differentiating stratified squamous epithelia [8].

\section{Metallothioneins MT-1 and MT-2}

Metallothioneins of both these groups will be discussed together under the term MT-1/2, due to their high structural homology and functional, as well as biological, similarities. MT- $1 / 2$ are built of the $\alpha$ domain (comprising amino acids 31-68) and the $\beta$ domain (comprising amino acids 1-30) [4]. The $\alpha$ domain comprises 11 cysteine residues capable of binding up to four divalent or six univalent metal ions, whereas the $\beta$ domain comprising of 9 cysteine residues was shown to bind up to three bivalent and six univalent metal ions [19]. Due to the high structural homology of these conserved proteins, antibodies against their antigenic domains are not capable of distinguishing particular MT-1/2 members [20]. MT-1/2 expression was shown in numerous studies to be induced by various agents such as heavy metals, steroid, free radicals, glucose, growth factors and cytokines. Among the above mentioned factors, zinc ions seem to be the main regulators of MT- $1 / 2$ expression in normal conditions [21-25]. Zinc ions regulate transcription of $M T-1 / 2$ genes via activation of metal response element-binding transcription factor 1 (MTF-1), leading to its subsequent linking by its zinc finger domains with a specific DNA region - the metal response element (MRE) in the MT-1/2 gene promoter [26, 27]. Besides, it was shown that metal ions other than zinc (e.g. cadmium and lead) may indirectly induce $M T-1 / 2$ transcription. Due to their higher affinity to MT-1/2, cadmium and lead ions displace zinc ions from the MT-1/2 molecule resulting in elevated intracellular zinc concentration. Zinc ions bind next to the MTF-1, which, in turn, increases the expression of MT-1/2 genes [28, 29]. Comparable mechanism was observed in regard to hydrogen peroxide $\left(\mathrm{H}_{2} \mathrm{O}_{2}\right)$ that oxidizes MTs molecules, which results in the release of zinc ions [30,31]. Moreover, the $M T-1 / 2$ transcription was also shown to be initiated independently of MTF-1 through the activation of other $M T-1 / 2$ promoter elements, such as antioxidant response element (ARE) during oxidative stress or glucocorticoid response element (GRE) in response to restrained stress conditions [32, 33].

MT- $1 / 2$ were shown to play important roles in various cellular processes. MT- $1 / 2$ regulate zinc ion homeostasis and may therefore regulate the activity of numerous transcription factors or zinc-dependent enzymes, e.g. metalloproteinases [34, 35]. Abundant lines of evidence point to the role of MT- $1 / 2$ in cell proliferation. Localization of MT-1/2 in proliferating cells depends on the phase of the cell cycle and was observed in nuclei, whereas in quiescent cells these isoforms are predominantly localized in the cytoplasm $[36,37]$. Biochemical studies showed that while in the G1 phase the highest concentrations of MT-1/2 are found in the cytoplasm, during the G1/S phase a translocation of MT-1/2 molecules into the nucleus may be observed [37]. Furthermore, the highest concentrations of MT- $1 / 2$ molecules were detected in the $\mathrm{S}$ and $\mathrm{G} 2$ phases of the cell cycle, which underlines their role in cell division [37, 38]. Cytoplasmic-nuclear expression of MT-1/2 was noted in regenerating kidney [39] and liver [40] as well as proliferating basal and parabasal cells of stratified epithelia [41]. The role of MT-1/2 in the activation of cell proliferation seems to be supported by studies showing its positive correlation with the expression $\mathrm{Ki}-67$ antigen in various tumors, e.g. breast cancer [42, 43], squamous and basal cell skin cancers [41, 44], adrenocortical cancers [45], 
non-small cell lung cancers $[19,46]$, gastrointestinal stromal tumors [47] and sarcomas [48].

Many studies provided evidences for the key role of MT- $1 / 2$ in the protection of DNA against damaging effects of free radicals $[49,50]$, whether induced by radiation [51-53] or chemotherapeutic agents, e.g. cisplatin, bleomycin, etoposide, melfalan or irinotecan during ovarian, gastric, breast or prostate cancer treatment [13, 54-60]. Furthermore, MT-1/2 may also diminish the cytotoxicity of some alkylating drugs, like cisplatin and carboplatin by binding to their heavy metal ions [4]. In relation to its free radical scavenging function, MT-1/2 isoforms were shown to be potent anti-inflammatory mediators protecting cells against carcinogenic compounds [61, 62]. Furthermore, the stimulatory role of MT-1/2 on angiogenesis and collaterogenesis under stress conditions such as hypoxia was also presented [63, 64]. Elevated levels of MT-1/2 protein found in hypoxic conditions were shown to stabilize expression of hypoxia-inducible factor- $1 \alpha(\mathrm{HIF}-1 \alpha)$ [65]. It was also found that MT1/2 may induce the expression of proangiogenic factors, e.g. fibroblast growth factor (FGF), transforming growth factor $\beta$ (TGF- $\beta$ ) and vascular endothelial growth factor A (VEGF-A) [19].

In spite of these apparently cytoprotective activities, in the majority of the studies MT- $1 / 2$ overexpression was associated with unfavorable prognosis in several malignancies, e.g. non-small cell lung cancer [66], intrahepatic cholangiocarcinoma [67], renal cancer [68], ovarian cancer [57], sarcoma [69] and melanoma [70]. However, in some tumors the prognostic significance of MT-1/2 expression seems to be limited, as in case of thyroid or laryngeal cancer [71, 72]; whereas in colorectal cancer high expression of MT-1 and MT-2 isoforms was associated with patient's favorable outcome [73]. Interestingly, the identification of particular isoforms of MT-1 and MT-2 revealed that not all of them were associated with patient's poor outcome. Some of them were shown to have cancer suppressive function. The MT-1G isoform was shown to be a potent oncosuppressor in papillary thyroid [74] and hepatocellular cancers [75], and MT-1F isoform - in colon cancer [76]. In contrast, the MT-2A isoform induces breast cancer cells proliferation and invasiveness via upregulation of matrix metalloproteinase- 9 expression as well as the chemoresistance $[35,58,77-79]$. The overexpression of MT-2A in osteosarcoma cells suppressed the antineoplastic activity of the p53 protein and rendered the cells chemoresistance towards doxorubicin [80]. These data may indicate that despite high structural homology of particular MT-1 and MT-2 isoforms, they may play different roles in normal and cancer cells.

\section{Metallothionein-3 (MT-3)}

MT-3 was first described as GIF (growth inhibitory factor), because of its unique inhibitory role in neuronal outgrowth $[14,81,82]$. It was first isolated from human brains affected by the Alzheimer disease [14]. Its expression was initially thought to be restricted only to the nervous system - glial cells and neurons, but further research identified the presence of MT-3 also in other tissues, like testis, epididymis, seminal vesicles, prostate gland, ovary, uterus, heart, tongue, and stomach of rat and components of genitourinary tract in humans [16,83-88].

MT-3 is built of 68 amino acids and, similarly to MT- $1 / 2$, organized into two domains, $\alpha$ and $\beta$. In spite of $70 \%$ structure homology, MT-3 molecule is characterized by the presence of a glutamate-rich hexapeptide containing a CPCP (Cys-Pro-Cys-Pro) motif localized near the C-terminus (amino acids 6-9). This unique peptide renders the structure of the MT-3 more nucleophilic and dynamic, and is probably responsible for the specific functions of MT-3 [81, 82]. The $\beta$-domain of the MT-3 molecule may bind only three bivalent ion metals, leaving two cysteine residues eligible. These residues may possibly participate in the interactions of MT-3 with thiol and disulfide groups of other proteins [89].

Although majority of studies suggest the uniform role of MT-1 and MT-2 isoforms in zinc ion homeostasis, scavenging of free radicals, proliferation, differentiation and apoptosis, studies analyzing the functions of MT-3 expression are not so consistent and bring divergent results. MT-3 was shown to exert protective effects, e.g. in in vitro models of epileptic brain and peripheral nerve injury [90]. However, the damage-promoting effects to neurons via highly increased intracellular zinc levels released from MT-3 molecules were also observed in in vitro studies [90]. Interestingly, also in other normal tissues and cancers frequently divergent results were observed in regard to the MT-3 function. The MT-3 immunoreactivity was found in normal human kidney [91] and in some cancer types; however, it varied strongly depending on the type of malignancy. Elevated expression of MT-3 mRNA, as well as MT-3 protein, was observed in prostate [16], breast [17, 88], and urinary bladder [18] cancers, whereas in gastric [83] and both types of esophageal cancer, i.e. squamous cell carcinoma and adenocarcinoma, expression of MT-3 mRNA was downregulated, but only in patients with methylated MT-3 promoter $[92,93]$. Taking into account that expression of MT-3 may additionally regulate lysosomal functions [90] and was shown to be induced in adipocytes under hypoxic conditions [94], further 


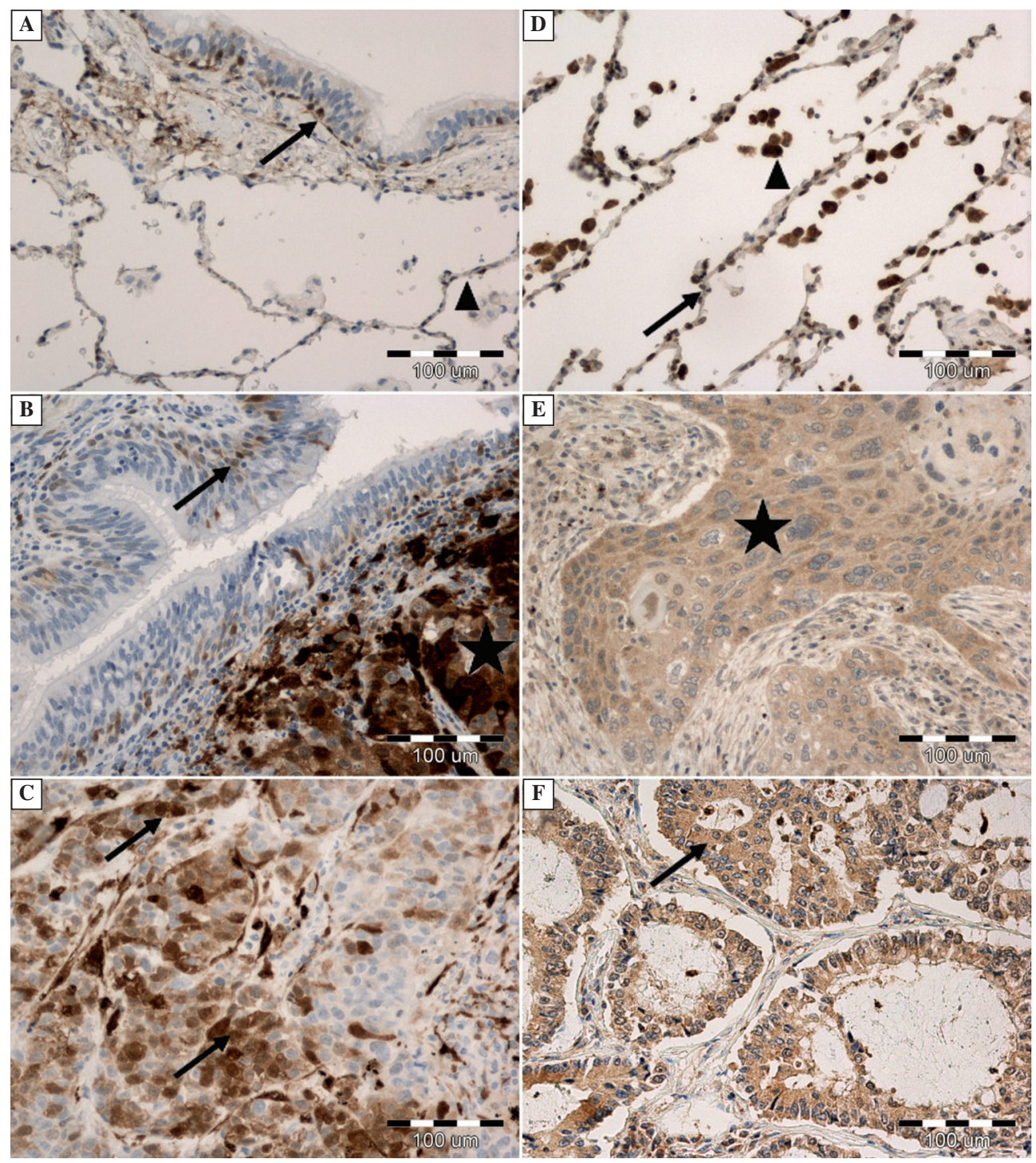

Figure 1. Immunohistochemical expression of MT-1/2 (A-C) and MT-3 (D-F) in normal lung and lung cancer. A. MT1/2 immunoreactivity is present in the nuclei of bronchial epithelial cells (arrow) and alveolar cells (arrowhead) of normal human lung; B. The presence of MT1/2 in the nuclei of bronchial epithelial cells (arrow) and in cytoplasm and nuclei of squamous cell carcinoma (SCC) cells (asterisk); C. MT1/2 presence in cytoplasm and nuclei of adenocarcinoma (AC) cells (arrow); D. MT-3 immunoreactivity in nuclei of alveolar cells (arrow) and alveolar macrophages (arrowhead) of normal human lung; E. MT-3 presence in the cytoplasm of SCC cells (asterisk); F. MT-3 in the cytoplasm of AC cells (arrow). The immunohistochemical reactions were performed by using commercial anti-MT-1/2 antibody (Clone E9, DakoCytomation, Denmark) and non-commercial, anti-MT-3 antibody (rabbit polyclonal antibody raised against GGEAAEAEAEKC peptide, Invitrogen, Carlsbad, USA). Normal human lung tissue was resected from non-malignant lung tissue adjacent to the primary lung tumor. Tumor tissue was obtained from patients during cancer resection

studies are needed to fully elucidate its role in carcinogenesis.

\section{Role of metallothioneins in lung physiology and pathology}

MTs were shown to be expressed in the cytoplasm and nuclei of normal pneumocytes and bronchial epithelial cells as well as cancer cells (Figure 1).
MT-1/2 were shown to protect lung tissue from several damaging agents such as bacterial endotoxin [95], ozone [96], carmustine (lipid soluble alkylating agent with high pulmonary toxicity) [97], ovalbumin (OVA) [98] and toxic metal ions such as cadmium [99-103]. It was demonstrated in human airway epithelial cells (BFAS-2B) that nickel increases MT-2A mRNA expression by mobilizing free intracellular zinc level [104]. MT-1/2 knock-out mice 
were more susceptible to lung edema induced by intratracheal challenge with lipopolysaccharide (LPS) as compared with wild type controls [95]. The most prominent changes were observed in endothelial cells of pulmonary vessels and type I alveolar epithelial cells. In these cells, vacuolar degeneration and loss of basement membranes following LPS treatment were noted; however, these alterations were not found in wild-type control mice [95]. Moreover, higher levels of lipid peroxides in the lung suggested that oxidative stress could be important damaging factor in the lungs of LPS-treated MT-1/2-deficient mice [95]. Similar observations of the changes of lung ultrastructure and oxidative stress-related molecules were noted in MT-1/2 knock-out mice subjected to ozone treatment [96]. Moreover, expression of the oxidative stress-related molecules, such as heme oxygenase- 1 (HO-1), inducible nitric oxide synthase (iNOS), levels of 8-hydroxy-2'-deoxyguanosine, and nitrotyrosine, were significantly higher in the lungs of MT- $1 / 2$ knock-out mice as compared with the control group [96]. Although ozone and LPS exposure damaged lungs of MT-1/2 deficient mice more intensely, no changes in the expression levels of proinflammatory cytokines in bronchoalveolar lavage (BAL) could be observed in both these studies $[95,96]$. Nevertheless, treatment of mice with ovalbumin led to much stronger increase of interleukin- $1 \beta$ levels in lungs of MT- $1 / 2$ knock-out mice as compared with wild type controls [98]. Similarly, 8-oxy-deoxyguanosine and nitrotyrosine levels were significantly higher in lungs of MT-1/2 knock-out mice which could indirectly indicate the protective function of MT-1/2 proteins against OVA-induced airway inflammation by oxidative damage suppression [98]. Taking into account the results of the above studies, besides MT-1/2 cytoprotective effects, its role of lung anti-inflammatory mediator and a possible marker of cell integrity can be implicated $[61,96]$.

The impact of MT-1/2 expression on tissue integrity and cell phenotype of pneumocytes and bronchial epithelial cells was also observed in in vivo and in vitro models following cadmium exposures; however, different mechanisms of action occurred in metal-intoxicated cells. Induction of MTs expression was noted following inhalation and intratracheal instillations of cadmium [99-103]. In lungs of Lewis rats pretreated with low dose of cadmium, increased MT-1/2 expression was found, which was associated with increased tolerance of the animals challenged with cadmium [101]. On the other hand, the cadmium adaptation of lung cells besides its protective effect for the lung was shown also to be a damaging factor for the lung cells [100]. A significant hyperplasia and hypertrophy of the alveolar epithelium in the lungs of cadmium-exposed animals was observed [100]. Cadmium adaptation may also stimulate alveolar epithelial cells to proliferate and in this way contribute to the carcinogenic process [100]. Moreover, cultured cadmium-adapted alveolar epithelial cells were shown to possess reduced ability of DNA repair and were more resistant to apoptotic stimuli $[100,102]$. To some extent in cadmium-pretreated alveolar cells, increased levels of MT-1/2 may sequester cadmium ions diminishing the cytotoxic effects of reactive oxygen species (ROS) [102]. However, at the same time these cells have reduced ability to repair the oxidative DNA damage once it occurred [102]. Recently conducted studies showed that epithelial lung cells (HPL-1D) chronically incubated with cadmium presented decrease in E-cadherin expression, a feature typical for cancer cells $[105,106]$.

According to Klaassen, intracellular MT-1/2 could diminish toxic effects of chronic cadmium-induced lung cells lesions such as pulmonary edema, hemorrhages, fibrotic changes and cancer [107].

On the other hand, in experimentally induced hyperoxia, MT-1/2 knock-out mice were characterized by decreased lung injury, such as reduced inflammation, interstitial edema and necrosis of airway epithelial cells, as compared with wild type controls [108]. Presumably, in the state of hyperoxia the lack of MT-1/2 is associated with observed increase of zinc ions level in the lung followed by compensatory increase in activity of antioxidant enzyme zinc-dependent superoxide dismutase (SOD) [108]. This may be a protective mechanism of airway epithelial cells against oxygen free radicals.

\section{Metallothioneins' expression in lung cancer cell lines}

Generally, the role of MTs in carcinogenesis has not been so far clearly defined, however, is seems that these proteins may exert only to some extent protective effects against heavy metal intoxication or ROS, implicated in the pathogenesis of some cancer types [109]. Once the protective potential of MTs has been reduced and neoplastic transformation took place, MTs may contribute strongly to tumor progression $[6,109]$. The data provided in the preceding chapter clearly suggest that MTs are crucial in the adaptation of normal airway epithelial cells to inhaled cadmium and other toxic metal ions. However, the insufficient adaptative response could lead to malignant transformation of epithelial cells as has been schematically shown in Figure 2.

Recently, the human lung cancer cell lines A549 and H441 were shown to respond to higher levels of cadmium and zinc by increasing expression of 


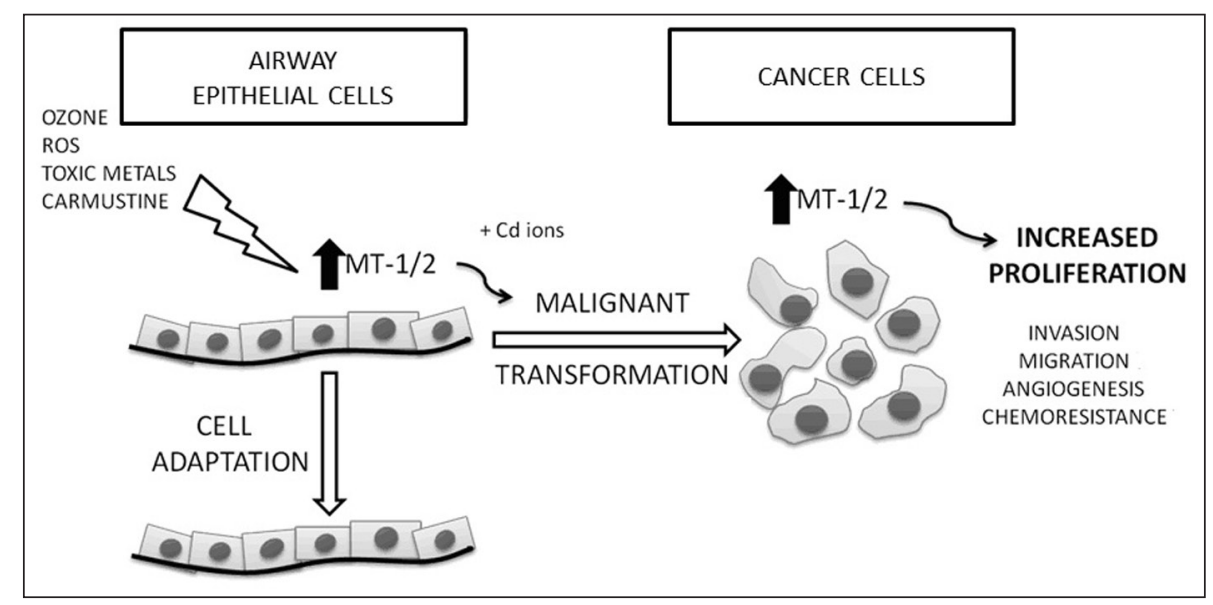

Figure 2. Possible action of MT-1/2 in normal airway epithelial cells and lung cancer cells. In response to noxious agents, an adaptive increase of MT-1/2 expression takes place in normal airway epithelial cells. The insufficient adaptive response could cause a malignant transformation of epithelial cells. Elevated MT1/2 expression in lung tumor cells is associated with increased cell proliferation and may have impact on invasion, migration, angiogenesis and chemoresistance of cancer cells

isoform MT-2A mRNA [110]. Moreover, in A549 cells an increase of another isoform, MT-1B, in response to nanosilver intoxication was observed [111]. Similarly, an increased level of MT-1/2 protein was also observed in A549 cells challenged with copper ions [112]. Concluding, these studies demonstrated that similarly to normal ones, also lung cancer cells respond to the increased level of metal ions by the upregulation of MTs expression. Most of the in vitro investigations were focused on determining the role of MT-1/2 in lung cancer cells' chemoresistance; however, they failed to establish any link between the MT-1/2 expression and resistance towards cisplatin and adriamycin $[113,114]$.

\section{Role of metallothioneins' expression in lung cancer}

Until now, only few studies analyzed the expression of MTs in lung cancer tumors in relation to clinicopathological data. Consistently across all studies, MT-1/2 levels were shown to be elevated in non-small cell lung cancer (NSCLC) cells as compared with normal epithelial airway cells $[19,115]$. Moreover, the analysis of MT- $1 / 2$ proteins expression in lung cancer cases revealed their presence only in both types of NSCLC, squamous cell carcinoma (SCC) and adenocarcinoma (AC), and absence of MT-1/2 proteins in small cell lung cancer (SCLC) [115]. In addition, MT-1/2 expression was noted in the tumor cells as well as in the stroma of the NSCLC. The higher levels of MT- $1 / 2$ were observed in the SCC in comparison to AC type, but MT- $1 / 2$ levels did not correlate with the grade of the tumors and lymph node metastases [115]. However, a study of Werynska et al. performed on high number of cases demonstrated the most pronounced expression of MT-1/2 in large cell carcinoma (LCC) as compared with AC [46]. Similarly to the observations of Theocharis et al., SCC presented significantly higher MT-1/2 levels as compared with AC cases. MT-1/2 immunoreactivity in cancer cells did not correlate with tumor malignancy grade, primary size, lymph node involvement or presence of necrosis [46]. To note, an increase of MT-1/2 immunoreactivity paralleling the increase of AC malignancy grade was observed [46]. However, the authors found a positive correlation of MT-1/2 expression with markers of proliferation (Ki-67 antigen and minichromosome maintenance protein 2-MCM2) in cancer cells, concordantly to some previous studies $[19,66]$. Despite the association of MT-1/2 expression with cellular proliferation markers, its immunoreactivity demonstrated no significant correlations with patient's survival and cancer prognosis [19, 46].

However, the molecular study of particular MTs isoforms in NSCLC and normal lung tissue revealed increased mRNA levels of $M T-1 B, M T-1 F, M T-1 G$, $M T-1 H, M T-1 X$ and $M T-3$ genes, decreased MT-1E expression and no expression of MT-4 isoform in NSCLC as compared with the normal lung tissue [20]. The high mRNA levels of $M T-1 A$ and $M T-1 F$ were associated with higher primary tumor size and highest malignancy grade [20]. Although MT-1/2 immunoreactivity had not have impact on NSCLC patients survival, cases with increased expression of $M T-1 F$ and $M T-2 A$ mRNA were characterized by poor outcome [20]. 
The potential role of MT-1/2 in the progression of SCLC is still poorly documented. It was demonstrated that high nuclear MT-1/2 immunoreactivity in this type of cancer cells was an independent predictive factor of patients' poor outcome [116].

A detailed analysis of immunohistochemical expression of MT-3 protein as well as expression of MT-3 mRNA was also performed in NSCLC [15]. The presence of MT-3 protein was observed both in the cytoplasm and nuclei of cancer cells. A significantly lower nuclear MT-3 immunoreactivity was observed in cancer cells of the most undifferentiated NSCLC cases while the SCC cases were characterized by high nuclear MT-3 expression [15]. In this study, the SCC cases presented favorable prognosis. In all analyzed NSCLC cases low cytoplasmic MT-3 expression was noted in cases with higher primary tumor size. In contrast to MT-1/2, nuclear as well as cytoplasmic MT-3 expression seems not to affect cancer cells proliferation, as no correlation with the expression of the Ki-67 antigen was observed [15]. Interestingly, lower MT-3 mRNA and cytoplasmic MT-3 expression were associated with poor patient outcome, but this finding was not confirmed in relation to MT-3 immunoreactivity in larger patients cohort [15].

The presented data suggest that the MT-1/2 and MT-3 expression in NSCLC seems to bear low prognostic and predictive role value, but may affect some processes during progression of this cancer, such as cancer cell proliferation. Further studies are needed to systemize and clarify the role of the MT family members in lung cancer.

\section{Acknowledgments}

The research was supported by Wroclaw Research Centre EIT+ under the project „Biotechnologies and advanced medical technologies" - BioMed (POIG.01.01.02-02-003/08) financed from the European Regional Development Fund (Operational Program Innovative Economy, 1.1.2).

\section{References}

1. Siegel R, Naishadham D, Jemal A. Cancer statistics 2013. CA Cancer J Clin. 2013;63:11-30. doi: 10.3322/caac.21166.

2. Szczuka I, Roszkowski-Sliz K. Lung cancer in Poland in 1970-2004. Pneumonol Alergol Pol. 2008;76:19-28. PMID: 18283651.

3. Detterbeck FC, Boffa DJ, Tanoue LT. The new lung cancer staging system. Chest. 2009;136:260-271. doi: 10.1378/ /chest.08-0978.

4. Dziegiel P. Expression of metallothioneins in tumor cells. Pol J Pathol. 2004;55:3-12. PMID: 15195701.

5. Vasak M, Meloni G. Chemistry and biology of mammalian metallothioneins.J Biol Inorg Chem. 2011;16:1067-1078. doi: 10.1007/s00775-011-0799-2.
6. Coyle P, Philcox JC, Carey LC, Rofe AM. Metallothionein: the multipurpose protein. Cell Mol Life Sci. 2002;59:627-647. PMID: 12022471.

7. Mididoddi S, McGuirt JP, Sens MA, Todd JH, Sens DA. Isoform-specific expression of metallothionein mRNA in the developing and adult human kidney. Toxicol Lett. 1996;85:17-27. doi: 10.1016/0378-4274(96)03632-6.

8. Quaife CJ, Findley SD, Erickson JC et al. Induction of a new metallothionein isoform (MT-IV) occurs during differentiation of stratified squamous epithelia. Biochemistry. 1994;33:7250-7259. PMID: 8003488.

9. Palmiter RD, Findley SD, Whitmore TE, Durnam DM. MT-III, a brain-specific member of the metallothionein gene family. Proc Natl Acad Sci USA. 1992;89:6333-6337. PMID: 1631128.

10. Stennard FA, Holloway AF, Hamilton J, West AK. Characterisation of six additional human metallothionein genes. Biochim Biophys Acta. 1994;1218:357-365. PMID: 8049263.

11. Olesen C, Moller M, Byskov AG. Tesmin transcription is regulated differently during male and female meiosis. Mol Reprod Dev. 2004;67:116-126. doi: 10.1002/mrd.20007.

12. Pula B, Domoslawski P, Podhorska-Okolow M, Dziegiel P. Role of metallothioneins in benign and malignant thyroid lesions. Thyroid Res. 2012;5:26. doi: 10.1186/1756-6614-5-26.

13. Pedersen MO, Larsen A, Stoltenberg M, Penkowa M. The role of metallothionein in oncogenesis and cancer prognosis. Prog Histochem Cytochem. 2009;44:29-64. doi: 10.1016/ j.proghi.2008.10.001.

14. Uchida Y, Takio K, Titani K, Ihara Y, Tomonaga M. The growth inhibitory factor that is deficient in the Alzheimer's disease brain is a 68 amino acid metallothionein-like protein. Neuron. 1991;7:337-347. doi: 10.1016/0896-6273(91)90272-2.

15. Werynska B, Pula B, Muszczynska-Bernhard B et al. Expression of metallothionein-III in patients with non-small cell lung cancer. Anticancer Res. 2013;33:965-974. PMID: 23482768.

16. Garrett SH, Sens MA, Shukla D et al. Metallothionein isoform 3 expression in the human prostate and cancer-derived cell lines. Prostate. 1999;41:196-202. doi: 10.1002/(SICI)10970045(19991101)41:3<196::AID-PROS7>3.0.CO;2-U.

17. Sens MA Somji S, Garrett SH, Beall CL, Sens DA. Metallothionein isoform 3 overexpression is associated with breast cancers having a poor prognosis. Am J Pathol. 2001;159:21-26. doi: 10.1016/S0002-9440(10)61668-9.

18. Sens MA, Somji S, Lamm DL et al. Metallothionein isoform 3 as a potential biomarker for human bladder cancer. Environ Health Perspect. 2000;108:413-418. PMID: 10811567.

19. Nielsen AE, Bohr A, Penkowa M. The balance between life and death of cells: roles of metallothioneins. Biomark Insights. 2007;1:99-111. PMID: 19690641.

20. Werynska B, Pula B, Muszczynska-Bernhard B et al. Metallothionein $1 \mathrm{~F}$ and $2 \mathrm{~A}$ overexpression predicts poor outcome of non-small cell lung cancer patients. Exp Mol Pathol. 2013;94:301-308. doi: 10.1016/j.yexmp.2012.10.006.

21. Haq F, Mahoney M, Koropatnick J. Signaling events for metallothionein induction. Mutat Res. 2003;533:211-226. doi: 10.1016/j.mrfmmm.2003.07.014.

22. Ghoshal K, Jacob ST. Regulation of metallothionein gene expression. Prog Nucleic Acid Res Mol Biol. 2001;66:357-384. PMID: 11051769.

23. Ghoshal K, Majumder S, Li Z, Bray TM, Jacob ST. Transcriptional induction of metallothionein-I and -II genes in the livers of $\mathrm{Cu}, \mathrm{Zn}$-superoxide dismutase knockout mice. Biochem Biophys Res Commun. 1999;264:735-742. doi: 10.1006/bbrc.1999.1563. 
24. Ghoshal K, Wang Y, Sheridan JF, Jacob ST. Metallothionein induction in response to restraint stress. Transcriptional control, adaptation to stress, and role of glucocorticoid. J Biol Chem. 1998;273:27904-27910. doi: 10.1074/jbc.273.43.27904.

25. Itoh N, Kasamatsu M, Onosaka S, Muto N, Tanaka K. Colchicine-induced elevation of tissue metallothionein contents is mediated by inflammation-independent serum factor. Toxicology. 1997;116:201-209. PMID: 9020522.

26. Saydam N, Adams TK, Steiner F, Schaffner W, Freedman JH. Regulation of metallothionein transcription by the metal-responsive transcription factor MTF-1: identification of signal transduction cascades that control metal-inducible transcription. J Biol Chem. 2002;277:20438-20445. doi: 10.1074/jbc. M110631200.

27. Langmade SJ, Ravindra R, Daniels PJ, Andrews GK. The transcription factor MTF-1 mediates metal regulation of the mouse ZnT1 gene. J Biol Chem. 2000;275:34803-34809. doi: 10.1074/jbc.M007339200.

28. Lichtlen P, Schaffner W. The "metal transcription factor" MTF-1: biological facts and medical implications. Swiss Med Wkly. 2001;131:647-652. PMID: 11835113.

29. Murata M, Gong P, Suzuki K, Koizumi S. Differential metal response and regulation of human heavy metal-inducible genes. J Cell Physiol. 1999;180:105-113. doi: 10.1002/ (SICI)1097-4652(199907)180:1<105::AID-JCP12>3.0. $\mathrm{CO} ; 2-5$.

30. Andrews GK. Regulation of metallothionein gene expression by oxidative stress and metal ions. Biochem Pharmacol. 2000;59:95-104. doi: 10.1016/S0006-2952(99)00301-9.

31. Nguyen T, Sherratt PJ, Pickett CB. Regulatory mechanisms controlling gene expression mediated by the antioxidant response element. Annu Rev Pharmacol Toxicol. 2003;43:233-260. doi: 10.1146/annurev.pharmtox.43.100901.140229.

32. Hernandez J, Carrasco J, Belloso E et al. Metallothionein induction by restraint stress: role of glucocorticoids and IL-6. Cytokine. 2000;12:791-796. doi: 10.1006/cyto.1999.0629.

33. Campagne MV, Thiobodeaux H, van Bruggen N, Cairns B, Lowe DG. Increased binding activity at an antioxidant-responsive element in the metallothionein-1 promoter and rapid induction of metallothionein- 1 and -2 in response to cerebral ischemia and reperfusion. $J$ Neurosci. 2000;20:5200-5207. PMID: 10884303.

34. Ostrakhovitch EA, Olsson PE, von Hofsten J, Cherian MG. P53 mediated regulation of metallothionein transcription in breast cancer cells. J Cell Biochem. 2007;102:1571-1583. doi: $10.1002 / j \mathrm{cb} .21381$.

35. Kim HG, Kim JY, Han EH et al. Metallothionein-2A overexpression increases the expression of matrix metalloproteinase-9 and invasion of breast cancer cells. FEBS Lett. 2011;585:421-428. doi: 10.1016/j.febslet.2010.12.030.

36. Apostolova MD, Ivanova IA, Cherian MG. Signal transduction pathways, and nuclear translocation of zinc and metallothionein during differentiation of myoblasts. Biochem Cell Biol. 2000;78:27-37. PMID: 10735561.

37. Cherian MG, Apostolova MD. Nuclear localization of metallothionein during cell proliferation and differentiation. Cell Mol Biol (Noisy-le-grand). 2000;46:347-356. PMID: 10774924.

38. Levadoux-Martin M, Hesketh JE, Beattie JH, Wallace HM. Influence of metallothionein-1 localization on its function. Biochem J. 2001;355:473-479. PMID: 11284736.

39. Zalups RK, Fraser J, Koropatnick J. Enhanced transcription of metallothionein genes in rat kidney: effect of uninephrectomy and compensatory renal growth. Am J Physiol. 1995;268:F643-F650. PMID: 7733321.
40. Cherian MG, Kang YJ. Metallothionein and liver cell regeneration. Exp Biol Med (Maywood). 2006;231:138-144. PMID: 16446489.

41. Zamirska A, Matusiak Ł, Dziegiel P, Szybejko-Machaj G, Szepietowski JC. Expression of metallothioneins in cutaneous squamous cell carcinoma and actinic keratosis. Pathol Oncol Res. 2012;18:849-855. doi: 10.1007/s12253-012-9513-0.

42. Gomulkiewicz A, Podhorska-Okolow M, Szulc R et al. Correlation between metallothionein (MT) expression and selected prognostic factors in ductal breast cancers. Folia Histochem Cytobiol. 2010;48:242-248. doi: 10.2478/v10042-010-0011-5.

43. Wojnar A, Pula B, Piotrowska A et al. Correlation of intensity of MT-I/II expression with $\mathrm{Ki}-67$ and MCM-2 proteins in invasive ductal breast carcinoma. Anticancer Res. 2011;31:3027-3033. PMID: 21868554.

44. Bieniek A, Pula B, Piotrowska A et al. Expression of metallothionein I/II and Ki-67 antigen in various histological types of basal cell carcinoma. Folia Histochem Cytobiol. 2012;50:352-357. doi: 10.5603/19744.

45. Szajerka A, Dziegiel P, Szajerka T, Zabel M, Winowski J, Grzebieniak Z. Immunohistochemical evaluation of metallothionein, Mcm-2 and Ki-67 antigen expression in tumors of the adrenal cortex. Anticancer Res. 2008;28:2959-2965. PMID: 19031940.

46. Werynska B, Pula B, Muszczynska-Bernhard B et al. Correlation between expression of metallothionein and expression of Ki-67 and MCM-2 proliferation markers in non-small cell lung cancer. Anticancer Res. 2011;31:2833-2839. PMID: 21868526.

47. PulaB,Strutynska-Karpinska M,Markowska-WoyciechowskaA et al. Expression of metallothionein and Ki-67 antigen in GISTs of different grade of malignancy. Adv Clin Exp Med. 2013;22:513-518. PMID: 23986211.

48. DziegielP, Salwa-Zurawska W,ZurawskiJ, Wojnar A,Zabel M. Prognostic significance of augmented metallothionein (MT) expression correlated with Ki-67 antigen expression in selected soft tissue sarcomas. Histol Histopathol. 2005;20:83-89. PMID: 15578426.

49. Ruttkay-Nedecky B, Nejdl L, Gumulec J et al. The role of metallothionein in oxidative stress. Int J Mol Sci. 2013;14:6044-6066. doi: 10.3390/ijms14036044.

50. Gwinner W, Grone HJ. Role of reactive oxygen species in glomerulonephritis. Nephrol Dial Transplant. 2000;15:1127-1132. doi: $10.1093 / \mathrm{ndt} / 15.8 .1127$.

51. Cai L, Cherian MG. Zinc-metallothionein protects from DNA damage induced by radiation better than glutathione and copper- or cadmium-metallothioneins. Toxicol Lett. 2003;136:193-198. doi: 10.1016/S0378-4274(02)00359-4.

52. Cai L, Satoh M, Tohyama C, Cherian MG. Metallothionein in radiation exposure: its induction and protective role. Toxicology. 1999;132:85-98. PMID: 10433372.

53. Deng DX, Satoh M, Tohyama C, Cherian MG. Increased radiation-induced apoptosis in mouse thymus in the absence of metallothionein. Toxicology. 1999;134:39-49. doi: 10.1016/ /S0300-483X(99)00026-8.

54. Smith DJ, Jaggi M, Zhang W et al. Metallothioneins and resistance to cisplatin and radiation in prostate cancer. Urology. 2006;67:1341-1347. doi: 10.1016/j.urology.2005.12.032.

55. Chun JH, Kim HK, Kim E et al. Increased expression of metallothionein is associated with irinotecan resistance in gastric cancer. Cancer Res. 2004;64:4703-4706. doi: 10.1158/00085472.CAN-04-1063.

56. Surowiak P, Materna V, Kaplenko I et al. Augmented expression of metallothionein and glutathione S-transferase pi as unfavourable prognostic factors in cisplatin-treated 
ovarian cancer patients. Virchows Arch. 2005;447:626-633. doi: 10.1007/s00428-005-1228-0.

57. Surowiak P, Materna V, Maciejczyk A et al. Nuclear metallothionein expression correlates with cisplatin resistance of ovarian cancer cells and poor clinical outcome. Virchows Arch. 2007;450:279-285. doi: 10.1007/s00428-006-0362-7.

58. Yap X, Tan HY, Huang J et al. Over-expression of metallothionein predicts chemoresistance in breast cancer. J Pathol. 2009;217:563-570. doi: 10.1002/path.2489.

59. Shimoda R, Achanzar WE, Qu W et al. Metallothionein is a potential negative regulator of apoptosis. Toxicol Sci. 2003;73:294-300. doi: 10.1093/toxsci/kfg095.

60. Okazaki Y, Miura N, Satoh M, Imura N, Naganuma A. Metallothionein-mediated resistance to multiple drugs can be induced by several anticancer drugs in mice. Biochem Biophys Res Commun. 1998;245:815-818. doi: 10.1006/bbrc.1998.8509.

61. Inoue K, Takano H, Shimada A, Satoh M. Metallothionein as an anti-inflammatory mediator. Mediat Inflamm. 2009;2009:101659. doi: 10.1155/2009/101659.

62. Takaishi M, Shimada A, Suzuki JS, Satoh M, Nagase H. Involvement of metallothionein (MT) as a biological protective factor against carcinogenesis induced by benzo[a]pyrene $(\mathrm{B}[\mathrm{a}] \mathrm{P})$. J Toxicol Sci. 2010;35:225-230. doi: 10.2131/jts.35.225.

63. Zbinden S, Wang J, Adenika R et al. Metallothionein enhances angiogenesis and arteriogenesis by modulating smooth muscle cell and macrophage function. Arterioscler Thromb Vasc Biol. 2010;30:477-482. doi: 10.1161/ATVBAHA.109.200949.

64. Miyashita H, Sato Y. Metallothionein 1 is a downstream target of vascular endothelial zinc finger 1 (VEZF1) in endothelial cells and participates in the regulation of angiogenesis. Endothelium. 2005;12:163-170. PMID: 16162438.

65. Kojima I, Tanaka T, Inagi R et al. Metallothionein is upregulated by hypoxia and stabilizes hypoxia-inducible factor in the kidney. Kidney Int. 2009;75:268-277. doi: 10.1038/ki.2008. 488.

66. Dziegiel P, Jelen M, Muszczynska B et al. Role of metallothionein expression in non-small cell lung carcinomas. Rocz Akad Med Bialymst. 2004;49:43-45. PMID: 15638370.

67. Schmitz KJ, Lang H, Kaiser G, Wohlschlaeger J et al. Metallothionein overexpression and its prognostic relevance in intrahepatic cholangiocarcinoma and extrahepatic hilar cholangiocarcinoma (Klatskin tumors). Hum Pathol. 2009;40:1706-1714. doi: 10.1016/j.humpath.2009.01.026.

68. Tuzel E, Kirkali Z, Yörükoglu K, Mungan MU, Sade M. Metallothionein expression in renal cell carcinoma: subcellular localization and prognostic significance. $J$ Urol. 2001;165:1710-1713. doi: 10.1016/S0022-5347(05)66399-9.

69. Dziegiel P, Suder E, Surowiak P, Kornafel J, Zabel M. Expression of metallothionein in synovial sarcoma cells. Appl Immunohistochem Mol Morphol. 2002;10:357-362. PMID: 12607605.

70. Weinlich G, Zelger B. Metallothionein overexpression, a highly significant prognostic factor in thin melanoma. Histopathology. 2007;51:280-283. doi: 10.1111/j.1365-2559.2007.02744.x.

71. Krolicka A, Kobierzycki C, Puła B et al. Comparison of metallothionein (MT) and Ki-67 antigen expression in benign and malignant thyroid tumours. Anticancer Res. 2010;30:4945-4949. PMID: 21187474.

72. Pastuszewski W, Dziegiel P, Krecicki T et al. Prognostic significance of metallothionein, $\mathrm{p} 53$ protein and Ki-67 antigen expression in laryngeal cancer. Anticancer Res. 2007;27:335-342. PMID: 17352251.

73. Arriaga JM, Levy EM, Bravo AI et al. Metallothionein expression in colorectal cancer: relevance of different isoforms for tumor progression and patient survival. Hum Pathol. 2012;43:197-208. doi: 10.1016/j.humpath.2011.04.015.

74. Ferrario C, Lavagni P, Gariboldi M et al. Metallothionein $1 \mathrm{G}$ acts as an oncosupressor in papillary thyroid carcinoma. Lab Invest. 2008;88:474-481. doi: 10.1038/labinvest.2008.17.

75. Kanda M, Nomoto S, Okamura Y et al. Detection of metallothionein $1 \mathrm{G}$ as a methylated tumor suppressor gene in human hepatocellular carcinoma using a novel method of double combination array analysis. Int J Oncol. 2009;35:477-483. doi: 10.3892/ijo_00000359.

76. Yan DW, Fan JW, Yu ZH et al. Downregulation of metallothionein $1 \mathrm{~F}$, a putative oncosuppressor, by loss of heterozygosity in colon cancer tissue. Biochim Biophys Acta. 2012;1822:918-926. doi: 10.1016/j.bbadis.2012.02.021.

77. Lai Y, Lim D, Tan PH et al. Silencing the Metallothionein-2A gene induces entosis in adherent MCF-7 breast cancer cells. Anat Rec (Hoboken). 2010;293:1685-1691. doi: 10.1002/ /ar.21215.

78. Jin R, Chow VT, Tan PH et al. Metallothionein 2A expression is associated with cell proliferation in breast cancer. Carcinogenesis. 2002;23:81-86. doi: 10.1093/carcin/23.1.81.

79. Lim D, Jocelyn KM, Yip GW, Bay BH. Silencing the Metallothionein-2A gene inhibits cell cycle progression from G1- to S-phase involving ATM and cdc25A signaling in breast cancer cells. Cancer Lett. 2009;276:109-117. doi: 10.1016/j. canlet.2008.10.038

80. Habel N, Hamidouche Z, Girault I et al. Zinc chelation: a metallothionein 2A's mechanism of action involved in osteosarcoma cell death and chemotherapy resistance. Cell Death Dis. 2013;4:e874. doi: 10.1038/cddis.2013.405.

81. Tsuji S, Kobayashi H, Uchida Y, Ihara Y, Miyatake T. Molecular cloning of human growth inhibitory factor cDNA and its down-regulation in Alzheimer's disease. EMBO J. 1992;11:4843-4850. PMID: 1464312.

82. Ding ZC, Ni FY, Huang ZX. Neuronal growth-inhibitory factor (metallothionein-3): structure-function relationships. FEBS J. 2010;277:2912-2920. doi: 10.1111/j. 1742-4658.2010.07716.x.

83. Deng D, El-Rifai W, Ji J et al. Hypermethylation of metallothionein-3 CpG island in gastric carcinoma. Carcinogenesis. 2003;24:25-29. doi: 10.1093/carcin/24.1.25.

84. Bathula CS, Garrett SH, Zhou XD et al. Cadmium, vectorial active transport, and MT-3-dependent regulation of cadherin expression in human proximal tubular cells. Toxicol Sci. 2008;102:310-318. doi: 10.1093/toxsci/kfn004.

85. Hoey JG, Garrett SH, Sens MA, Todd JH, Sens DA. Expression of MT-3 mRNA in human kidney, proximal tubule cell cultures, and renal cell carcinoma. Toxicol Lett. 1997;92:149-160. doi: 10.1016/S0378-4274(97)00049-0.

86. Somji S, Garrett SH, Sens MA, Gurel V, Sens DA. Expression of metallothionein isoform 3 (MT-3) determines the choice between apoptotic or necrotic cell death in $\mathrm{Cd}+2$-exposed human proximal tubule cells. Toxicol Sci. 2004;80:358-366. doi: $10.1093 /$ toxsci/kfh158.

87. Somji S, Garrett SH, Toni C, Zhou XD. Differences in the epigenetic regulation of MT-3 gene expression between parental and $\mathrm{Cd}+2$ or $\mathrm{As}+3$ transformed human urothelial cells. Cancer Cell Int. 2011;11:2. doi: 10.1186/1475-2867-11-2.

88. Somji S, Garrett SH, Zhou XD et al. Absence of metallothionein 3 expression in breast cancer is a rare, but favorable marker of outcome that is under epigenetic control. Toxicol Environ Chem. 2010;92:1673-1695. doi: 10.1080/02772241003711274.

89. Meloni G, Faller P, Vasak M. Redox silencing of copper in metal-linked neurodegenerative disorders: reaction 
of Zn7metallothionein-3 with Cu2+ ions. J Biol Chem. 2007;282:16068-16078. doi:10.1074/jbc.M701357200.

90. Lee SJ, Park MH, Kim HJ, Koh JY. Metallothionein-3 regulates lysosomal function in cultured astrocytes under both normal and oxidative conditions. Glia. 2010;58:1186-1196. doi: 10.1002/glia.20998.

91. Garrett SH, Sens MA, Todd JH, Somji S, Sens DA. Expression of MT-3 protein in the human kidney. Toxicol Lett. 1999;105:207-214. doi: 10.1016/S0378-4274(99)00003-X.

92. Smith E, Drew PA, Tian ZQ et al. Metallothionien 3 expression is frequently down-regulated in oesophageal squamous cell carcinoma by DNA methylation. Mol Cancer. 2005;4:42. doi: 10.1186/1476-4598-4-42.

93. Peng D, Hu TL, Jiang A et al. Location-specific epigenetic regulation of the metallothionein 3 gene in esophageal adenocarcinomas. PLoS One. 2011;6:22009. doi: 10.1371/journal. pone.0022009.

94. Wang B, Wood IS, Trayhurn P. PCR arrays identify metallothionein-3 as a highly hypoxia-inducible gene in human adipocytes. Biochem Biophys Res Commun. 2008;368:88-93. doi: 10.1016/j.bbrc.2008.01.036.

95. Takano $\mathrm{H}$, Inoue $\mathrm{K}$, Yanagisawa $\mathrm{R}$ et al. Protective role of metallothionein in acute lung injury induced by bacterial endotoxin. Thorax. 2004;59:1057-1062. doi:10.1136/ /thx.2004.024232.

96. Inoue K, Takano H, Kaewamatawong T et al. Role of metallothionein in lung inflammation induced by ozone exposure in mice. Free Radic Biol Med. 2008;45:1714-1722. doi: 10.1016/ /j.freeradbiomed.2008.09.008.

97. Helal GK, Helal OK. Metallothionein attenuates carmustine-induced oxidative stress and protects against pulmonary fibrosis in rats. Arch Toxicol. 2009;83:87-94. doi: 10.1007/ /s00204-008-0325-7.

98. Inoue K, Takano H, Yanagisawa R et al. Role of metallothionein in antigen-related airway inflammation. Exp Biol Med (Maywood). 2005;230:75-81. PMID: 15618129

99. Hart BA, Gong Q, Eneman JD, Durieux-Lu CC. In vivo expression of metallothionein in rat alveolar macrophages and type II epithelial cells following repeated cadmium aerosol exposures. Toxicol Appl Pharmacol. 1995;133:82-90. doi: 10.1006/taap.1995.1129.

100. Hart BA, Potts RJ, Watkin RD. Cadmium adaptation in the lung - a double-edged sword? Toxicology. 2001;160:65-70. doi: 10.1016/S0300-483X(00)00436-4.

101. Hart BA, Voss GW, Willean CL. Pulmonary tolerance to cadmium following cadmium aerosol pretreatment. Toxicol Appl Pharmacol. 1989;101:447-460. PMID: 2481347.

102. Potts RJ, Bespalov IA, Wallace SS, Melamede RJ, Hart BA. Inhibition of oxidative DNA repair in cadmium-adapted alveolar epithelial cells and the potential involvement of metallothionein. Toxicology. 2001;161:25-38. doi: 10.1016/ /S0300-483X(00)00419-4.

103. Kenaga C, Cherian MG, Cox C, Oberdörster G. Metallothionein induction and pulmonary responses to inhaled cadmium chloride in rats and mice. Fundam Appl Toxicol. 1996;30:204-212. PMID: 8812267.

104. Nemec AA, Leikauf GD, Pitt BR, Wasserloos KJ, Barchowsky A. Nickel mobilizes intracellular zinc to induce metallothionein in human airway epithelial cells. Am J Respir Cell Mol Biol. 2009;41:69-75. doi: 10.1165/rcmb.2008-0409OC.

105. Person RJ, Tokar EJ, Xu Y, Orihuela R, Ngalame NN, Waalkes MP. Chronic cadmium exposure in vitro induces cancer cell characteristics in human lung cells. Toxicol Appl Pharmacol. 2013;273:281-288. doi: 10.1016/j.taap.2013.06.013.

106. Pearson CA, Lamar PC, Prozialeck WC. Effects of cadmium on E-cadherin and VE-cadherin in mouse lung. Life Sci. 2003;72:1303-1320. doi: 10.1016/S0024-3205(02)02379-2.

107. Klaassen CD, Liu J, Diwan BA. Metallothionein protection of cadmium toxicity. Toxicol Appl Pharmacol. 2009;238:215-220. doi: 10.1016/j.taap.2009.03.026.

108. Lee SM, McLaughlin JN, Frederick DR et al. Metallothionein-induced zinc partitioning exacerbates hyperoxic acute lung injury. Am J Physiol Lung Cell Mol Physiol. 2013;304:L350-L360. doi: 10.1152/ajplung.00243.2012.

109. McGee HM, Woods GM, Bennett B, Chung RS. The two faces of metallothionein in carcinogenesis: photoprotection against UVR-induced cancer and promotion of tumour survival. Photochem Photobiol Sci. 2010;9:586-596. doi: 10.1039/ /b9pp00155g.

110. Sauvageau JA, Jumarie C. Different mechanisms for metal-induced adaptation to cadmium in the human lung cell lines A549 and H441. Cell Biol Toxicol. 2013;29:159-173. doi: 10.1007/s10565-013-9243-4.

111. Foldbjerg R, Irving ES, Hayashi Y et al. Global gene expression profiling of human lung epithelial cells after exposure to nanosilver. Toxicol Sci. 2012;130:145-157. doi: 10.1093/ /toxsci/kfs225.

112. Arnal N, de Alaniz MJ, Marra CA. Effect of copper overload on the survival of HepG2 and A-549 human-derived cells. Hum Exp Toxicol. 2013;32:299-315. doi: 10.1177/0960327112456313.

113. Gansukh T, Donizy P, Halon A, Lage H, Surowiak P. In vitro analysis of the relationships between metallothionein expression and cisplatin sensitivity of non-small cellular lung cancer cells. Anticancer Res. 2013;33:5255-5260. PMID: 24324058.

114. Hatcher EL, Alexander JM, Kang YJ. Decreased sensitivity to adriamycin in cadmium-resistant human lung carcinoma A549 cells. Biochem Pharmacol. 1997;53:747-754. doi:10.1016/ /S0006-2952(96)00811-8.

115. Theocharis S, Karkantaris C, Philipides T et al. Expression of metallothionein in lung carcinoma: correlation with histological type and grade. Histopathology. 2002;40:143-151. doi: 10.1046/j.1365-2559.2002.01325.x.

116. Joseph MG, Banerjee D, Kocha W, Feld R, Stitt LW, Cherian MG. Metallothionein expression in patients with small cell carcinoma of the lung: correlation with other molecular markers and clinical outcome. Cancer. 2001;92:836-842. PMID: 11550155. 